lo lắng đạt $5,49(S D= \pm 3,31)$ min 3,8 và $\max 6$ và tổng điểm CLCS là 27,43 $(\mathrm{SD}= \pm 3,31)$ cao hơn so với nghiên cứu tại Pakistan đạt 4,78 (SD $= \pm 1,75)$ với min 1 và max 7 và tổng điểm $C L C S$ là 23,92 (SD = =7,68).[2] Và thấp hơn so với nghiên cứu của tại Brazil năm 2012 có tổng điểm CLCS là 25,69 (SD = =9,99).[4]

\section{KẾT LUÂ̂N}

Điểm trung bình CLCS của người bệnh xơ gan trong nghiên cứu là 4,71 (SD = 00,69$)$. Đặc biệt dấu mệt mỏi của người bệnh xơ gan cần phải được quản lý chặt chẽ hơn vì trong nghiên cứu này điểm số mệt mỏi thấp nhất trong các thành phần điểm của chất lượng cuộc sống người bệnh $x \widetilde{o}$ gan (Mean $=4,26 ; \dot{S D}= \pm 0,94$ ).

\section{TÀI LIÊU THAM KHẢO}

1. Bùi Thế Anh, (2019). "Đánh giá chất lượng cuộc sống của người bệnh ung thư thanh quản trước và sau phẩu thuật", Luận án tiến sỹ y học, Đại học Y Hà Nội.

2. Parkash, O., Iqbal, R., Jafri, F., Azam, I., \& Jafri, $\mathbf{W}$. (2012). Frequency of poor quality of life and predictors of health related quality of life in cirrhosis at a tertiary care hospital Pakistan. BMC research notes, 5,
https://doi.org/10.1186/1756-0500-5-446

3. Janani, K., Jain, M., Vargese, J., Srinivasan, V., Harika, K., Michael, T., \& Venkataraman, J. (2018). Health-related quality of life in liver cirrhosis patients using SF-36 and CLDQ questionnaires. Clinical and experimental hepatology, 4(4), 232-239. https://doi.org/10.5114/ceh.2018.80124

4. Souza, N. P., Villar, L. M., Garbin, A. J., Rovida, T. A., \& Garbin, C. A. (2015). Assessment of health-related quality of life and related factors in patients with chronic liver disease. The Brazilian journal of infectious disease: an official publication of the Brazilian Society of Infectious Diseases, 19(6), 590-595. https://doi.org/10.1016/j.bjid.2015.08.003

5. GBD 2017 Cirrhosis Collaborators (2020). The global, regional, and national burden of cirrhosis by cause in 195 countries and territories, 19902017: a systematic analysis for the Global Burden of Disease Study 2017. The lancet. Gastroenterology \& hepatology, 5(3), 245-266. https://doi.org/10.1016/S2468-1253(19)30349-8

6. WHO (2018). Liver cirrhosis $(15+)$, agestandardized death rates by country. Nguôn tài liệu https://apps.who.int/gho/data/view.main.53420

\title{
KẾT QUẢ ĐIỀU TRI ENDOXAN TĨNH MACH LIỀU CAO Ở BÊNH NHÂN LUPUS BAN ĐỎ HÊ̂ THÔNG ĐợT CẤP CÓ TỔN THƯƠNG THẦn CÓ THAY THẾ HUYẾT TƯƠNG TẠI KHOA THẬN TIẾT NIỆU BỆNH VIỆN BẠCH MAI
}

\author{
Trần Bích Ngọc ${ }^{1}$, Đỗ Gia Tuyển ${ }^{1,2}$, Nguyễn Gia Bình ${ }^{3}$
}

\section{TÓM TẮT}

Mục tiêu: Đánh giá thay đổi lâm sàng, xét nghiệm sau điều trị endoxan tĩnh mạch liêu cao 6 tháng ở bệnh nhân (BN) lupus ban đỏ hệ thống (LBĐHT) đợt cấp có tổn thương thận kết hợp thay thế huyết tương. Đối tượng và phương pháp nghiên cứu: 55 BN LBĐHT được điêu trị từ 10/2014-6/2018 tai khoa Thân Tiết niệu bênh viên Bach mai. Sau khi thay thế huyết tương 3 lần $\mathrm{BN}$ được điều trị bằng endoxan truyền tĩnh mạch liều cao $500 \mathrm{mg} / \mathrm{kg} / \mathrm{m}^{2} \mathrm{da}$ hàng tháng trong 6 tháng, kết hợp methylprednisolon. Phương pháp nghiên cứu: mô tả, tiến cứu. Kết quả: Sau điều trị: điểm SLEDAI giảm từ 24,1 45,5 xuống $11,5 \pm 6,1 ; p<0,00001$. Nồng độ kháng thể kháng DsDNA giảm từ $163,9 \pm 131,8$ xuống $75,3 \pm 76,1$

\footnotetext{
${ }^{1}$ Trung tâm Thận Tiết niệu-lọc máu, Bệnh viện Bạch mai ${ }^{2}$ Trường Đại học Y Hà Nội

${ }^{3}$ Bênh viện Bạch Mai

Chịu trách nhiệm chính: Trân Bích Ngọc

Email: tranbichngoc76@gmail.com

Ngày nhận bài: 5.5.2021

Ngày phản biện khoa học: 25.6.2021

Ngày duyệt bài: 5.7.2021
}

$\mathrm{IU} / \mathrm{ml} ; \mathrm{p}=0,005$. Về thân: mức loc câu thân (MLCT) đã tăng tứ $27,6 \pm 20,6$ lền $67,6 \pm 37,7 \mathrm{ml} / \mathrm{p} / 1,73 \mathrm{~m}^{2} \mathrm{da}$; $p<0,0001$. Đáp ứng thân hoàn toàn là $10,9 \%$, đáp ứng không hoàn toàn là 49,1\%. Kết luận: đây là phác đồ điêu trị mang lại hiệu quả, an toàn và có thể áp dụng trong điều kiện của nước ta.

Tư khóa: lupus, thay thế huyết tương, endoxan

\section{SUMMARY}

THE OUTCOME OF CONCURRENT

TREATMENT WITH 6-MONTH HIGH DOSE INTRAVENOUS ENDOXAN AND PLASMA

EXCHANGE FOR LUPUS NEPHRITIS FLARE IN NEPHRO-UROLOGY DEPARTMENT,

\section{BACH MAI HOSPITAL}

Objectives: evaluate the change in clinical, laboratory in patients with lupus nephritis flare to concurrent treatment with plasma exchange and high dose intravenous endoxan. Participants: 55 patients with lupus nephritis flare were given treatment from October 2014 to June 2018 in Bach mai Hospital. The standard regimen includes 3 sessions of plasma exchange, followed by monthly intravenous endoxan $\left(500 \mathrm{mg} / \mathrm{m}^{2} \mathrm{BSA}\right)$ for 6 months in combination with prolonged steroid. Methods: prospective study 
Outcomes: After 6 months, mean SLEDAI score decreased from $24.1 \pm 5.5$ to $11.5 \pm 6.1$ ( $p<0.00001$ ). Serum anti ds-DNA antibodies level decreased from $163.9 \pm 131.8 \mathrm{IU} / \mathrm{mL}$ to $75.3 \pm 76.1 \mathrm{IU} / \mathrm{mL}(p=0.005)$. Mean eGFR increased from $27.6 \pm 20.6$ to $67.6 \pm 37.7$ $\mathrm{ml} / \mathrm{min} / 1.73 \mathrm{~m}^{2}$. Complete renal response was $10.9 \%$, partial renal response $49.1 \%$. Conclusions: This treatment was efficient, safe and could be appropriate to apply in Vietnam.

Keywords: lupus nephritis, plasma exchange, cyclosphosphamid

\section{I. ĐĂT VẤN ĐỀ}

Lupus ban đỏ hệ thống là một trong các bênh miễn dịch hay gặp nhất trong các bệnh tự miễn, hay gặp ở người phụ nữ trẻ, và biểu hiện đa cơ quan $[1,2]$. Biểu hiện thận thường gặp và cũng là yếu tố tiên lượng nặng. Hiện nay, phác đồ thuốc được khuyến cáo là cyclophosphamid (Endoxan) hoăc mycophenolat mophetil (Cellcept) kết hợp với corticoide liêu cao [3]. Ngoài ra, bệnh nhân có thể được lọc bỏ các kháng thể bất thường, giúp cải thiện triệu chứng nhanh và tăng khả năng đáp ứng với thuốc [4]. Tại Việt nam hiện nay chưa có báo cáo đây đủ vể kết quả và tính an toàn của phương pháp điêu trị này, do đó kết quả nghiên cứu của chúng tôi sẽ góp phân là sáng tỏ vấn đề trên.

\section{II. ĐỐI TƯƠ'NG VÀ PHƯƠNG PHÁP NGHIÊN CỨU}

Đối tượng nghiên cứu: 55 bệnh nhân LBĐHT được lựa chọn theo tiêu chuẩn sau: trên 15 tuổi, có kèm theo tổn thương thận với protein niệu $24 \mathrm{~h} \geq 500 \mathrm{mg}$, hồng câu niệu dương tính, có thể có trụ niệu, có thể có suy chức năng thận. Thời gian từ 10/2014 đến 6/2018, tại khoa ThậnTiết niệu Bệnh viện Bạch mai. Bệnh nhân được đánh giá hoạt động lupus theo thang điểm SLEDAI, sinh thiết thận cho BN đủ điều kiện. Sau khi được thay thế huyết tương BN được điều trị bằng thuốc endoxan liều cao truyên tĩnh mạch. Tiêu chuẩn loại trừ là BN đang có nhiễm trùng cấp hoặc mạn tính nặng, dị ứng với huyết tương hoặc thuốc cyclophosphamid.

Phương pháp nghiên cứu: Áp dụng phác đồ endoxan truyền tĩnh mạch liêu cao $500 \mathrm{mg} / \mathrm{kg} / \mathrm{m}^{2}$ da cơ thể, tháng 1 lần trong 6 tháng liên tục. Bệnh nhân nữ trong độ tuổi sinh đẻ được hướng dẫn các biện pháp tránh thai, theo dõ̃i tác dụng không mong muốn. Số liệu thu thập được xử lý trên phân mềm Stata 12.0.

\section{KẾT QUẢ NGHIÊN CỨU}

55 BN trong nghiên cứu, 50 nữ và 5 nam (tỷ

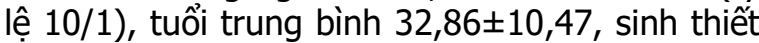
thận 48 BN (4 class III, 38 class IV, 3 class V).

Bảng 3.1. Thay đổi lâm sàng sau điều trị endoxan

\begin{tabular}{|c|c|c|c|}
\hline $\begin{array}{c}\text { Đắc điểm } \\
\text { lâm sàng }\end{array}$ & $\begin{array}{c}\text { Trước } \\
\text { điêuu trị } \\
\mathbf{n ( \% )}\end{array}$ & $\begin{array}{c}\text { Sau } \\
\text { endoxan } \\
\text { lân 3 } \\
\mathbf{n ( \% )}\end{array}$ & $\begin{array}{c}\text { Sau điêuu tr } \\
\text { endoxan 6 } \\
\text { lân n(\%) }\end{array}$ \\
\hline $\begin{array}{c}\text { Co giật, đau } \\
\text { đâu lupus }\end{array}$ & $9(16,4)$ & $1(1,8)$ & $0(0)$ \\
\hline Viêm mạch & $4(7,3)$ & $1(1,8)$ & $0(0)$ \\
\hline Viêm khớp & $17(30,9)$ & $0(0)$ & $0(0)$ \\
\hline $\begin{array}{c}\text { Ban cánh } \\
\text { bướm }\end{array}$ & $27(49,1)$ & $1(1,8)$ & $2(3,6)$ \\
\hline $\begin{array}{c}\text { Loét niêm } \\
\text { mạc }\end{array}$ & $2(3,6)$ & $0(0)$ & $0(0)$ \\
\hline Rụng tóc & $13(23,6)$ & $0(0)$ & $0(0)$ \\
\hline $\begin{array}{c}\text { Viêm màng } \\
\text { thanh dịch }\end{array}$ & $47(38,2)$ & $2(3,6)$ & $1(1,8)$ \\
\hline Sốt > 38 độ & $11(20,0)$ & $0(0)$ & $0(0)$ \\
\hline SLEDAI & $21,4 \pm 5,5$ & $12,9 \pm 5,3$ & $11,5 \pm 6,1$ \\
\hline
\end{tabular}

Nhân xét: Sau điều trị tất cả các triệu chứng theo thang điểm SLEDAI đều thuyên giảm so với trước điêu trị, trong đó điểm SLEDAI đã giảm khoảng 10 điểm và sự khác biệt có ý nghĩa với $p<0,0001$.

Bảng 3.2. Một số thay đổi xét nghiệm sau điêu trị endoxan

\begin{tabular}{|c|c|c|c|c|}
\hline $\begin{array}{l}\text { Đặc điếm lấm } \\
\text { sàng }\end{array}$ & $\begin{array}{l}\text { Trước } \\
\text { điều trị }\end{array}$ & $\begin{array}{l}\text { Sau truyền } \\
\text { endoxan } 3\end{array}$ & $\begin{array}{c}\text { Sau đîều } \\
\text { trị }\end{array}$ & $\mathbf{p}$ \\
\hline $\begin{array}{l}\text { ANA (+) } \\
\text { n(\%) }\end{array}$ & $53(96,4)$ & $45(81,8)$ & $45(81,8)$ & $\begin{array}{c}\mathrm{p}_{0-3}=0,33 ; \mathrm{p}_{0-6}=0,33 \\
\mathrm{p}_{3-6}<0,0001\end{array}$ \\
\hline $\begin{array}{c}\text { DsDNA(+) } \\
\mathrm{n}(\%)\end{array}$ & $38(69,1)$ & $25(45,5)$ & $24(43,6)$ & $\begin{aligned} \mathrm{p}_{0-3}= & 0,03 ; \mathrm{p}_{0-6}=0,009 \\
& \mathrm{p}_{3-6}<0,0001\end{aligned}$ \\
\hline $\begin{array}{l}\text { Protein niệu } \\
(\mathrm{g} / 24 \mathrm{~h})\end{array}$ & $9,19 \pm 7,71$ & $3,61 \pm 2,82$ & $2,55 \pm 2,37$ & $\begin{array}{c}\mathrm{p}_{0-3}<0,0001 ; \mathrm{p}_{0-6}<0,0001 \\
\mathrm{p}_{3-6}=0,004\end{array}$ \\
\hline $\begin{array}{c}\mathrm{MLCT} \\
\mathrm{ml} / \mathrm{ph} / 1,73 \mathrm{~m}^{2} \mathrm{da}\end{array}$ & $37,6 \pm 20,6$ & $59,3 \pm 29,7$ & $67,6 \pm 37,3$ & $\begin{array}{c}\mathrm{p}_{0-3}<0,0001 ; \mathrm{p}_{0-6}<0,0001 \\
\mathrm{p}_{3-6}=0,002\end{array}$ \\
\hline
\end{tabular}

Nhận xét: Sau điều trị nồng độ kháng thể kháng DsDNA, protein niệu 24h giảm và MLCT tăng rõ rệt so với trước điều trị, khác biệt có nghĩa thống kê với $p<0,0001$. 
Bảng 3.3. Đánh giá mức độ đáp ứng thận sau điều trị

\begin{tabular}{|c|c|c|c|}
\hline \multirow{2}{*}{ Thời điểm } & \multicolumn{3}{|c|}{ Đáp ứng thân } \\
\cline { 2 - 4 } & $\begin{array}{c}\text { Hoàn } \\
\text { toàn }\end{array}$ & $\begin{array}{c}\text { Không } \\
\text { hoàn toàn }\end{array}$ & $\begin{array}{c}\text { Không } \\
\text { đáp ứng }\end{array}$ \\
\hline $\begin{array}{c}\text { Sau endoxan } \\
\text { lần } 3\end{array}$ & $\begin{array}{c}5 \\
(9,09)\end{array}$ & $20(36,36)$ & $30(54,55)$ \\
\hline Sau điều trị & $\begin{array}{c}6 \\
(10,91)\end{array}$ & $27(49,09)$ & $22(40,00)$ \\
\hline
\end{tabular}

Nhận xét: Sau điêu trị $60 \%$ bệnh nhân có đáp ứng thận (đáp ứng hoàn toàn 10,9\%; đáp ứng khồng hoàn toàn 49,1\%), 40\% bệnh nhân không có đáp ứng.

Bảng 3.4. Các tác dụng không mong muốn được ghi nhận trong điều trị endoxan

\begin{tabular}{|c|c|c|}
\hline $\begin{array}{c}\text { Tác dụng không mong } \\
\text { muốn }\end{array}$ & $\begin{array}{c}\text { Tân số } \\
\text { (n) }\end{array}$ & $\begin{array}{c}\text { Tỷ lệ } \\
\mathbf{( \% )}\end{array}$ \\
\hline Buồn nôn, nôn trong truyền & 15 & 27,27 \\
\hline Sốt hoặc co giật & 2 & 3,64 \\
\hline Vô kinh sau truyền & 5 & 9,10 \\
\hline $\begin{array}{c}\text { Nhiêm khuấn (viêm phối/ } \\
\text { NKTN/zona) }\end{array}$ & 8 & 14,55 \\
\hline
\end{tabular}

Nhận xét: Trong quá trình truyền endoxan BN có xuất hiện các triệu chứng nôn, buồn nôn( $27,27 \%)$, sốt $>38$ độ (1 BN; $1,82 \%)$, co giật (1 BN;1,82\%), nhiễm khuẩn do vi khuân (7 BN; $12.72 \%)$ gồm viêm phổi hoặc nhiễm khuẩn tiết niệu (NKTN), zona thần kinh (1 BN; $1.82 \%)$. Sau truyền endoxan xuất hiện vô kinh $(9,1 \%)$. Không có $B N$ đái máu, xơ phổi, ung thư thứ phát. Không có BN tử vong.

\section{BÀN LUÂN}

Trong nghiên cứu có $55 \mathrm{BN}$, nữ/nam là 10/1, tuổi trung bình $32,86 \pm 10,47$. Sau điều trị hầu hết các biểu hiện lâm sàng đều thuyên giảm, tương tự nhận xét trong các nghiên cứu các tác giả nước ngoài $[1,2]$. Bên cạnh đó, mức độ dương tính của kháng thể kháng DsDNA giảm, $p<0,0001$. Về thận, protein niệu $24 \mathrm{~h}$ đã giảm dần trong 6 tháng với khác biệt $p<0,001$; trung bình xuống dưới ngưỡng thận hư làm cho đáp ứng thận tăng dần. Tuy nhiên, đáp ứng hoàn toàn của chúng tôi $10,9 \%$, thấp hơn môtt số nghiên cứu khác có thể do có thay đổi về tiêu chuẩn đánh giá về đáp ứng protein niệu $[2,5]$. Tỷ lệ có đáp ứng thận gồm đáp ứng hoàn toàn và không hoàn toàn đạt mức $60 \%$, kết quả này cũng tương tự với một số nghiên cứu trên thế giới $[6,7]$. Bệnh nhân không đáp ứng là $40 \%$ với đặc điểm bệnh lupus diễn biến nhiều năm, tổn thương mô bệnh học thận mức độ nặng, điểm mạn tính cao, theo khuyến cáo cần thay đổi phác đồ hoặc phối hợp thêm thuốc [5].

Khía cạnh an toàn về thuốc, nghiên cứu này thấy ít tác dụng nghiêm trọng phù hợp với khuyến cáo [8]. Hơn nữa, chúng tôi cũng đã áp dụng hướng dần sử dụng thuốc như truyền kết hợp với Uromitexan, uống nhiều nước và đi tiểu thường xuyên để tránh chảy máu bàng quang. Bệnh nhân gặp nhiễm khuẩn và zona thần kinh $(14,55 \%)$, gồm nhiễm khuẩn phổi và nhiễm khuẩn tiết niệu đã được điều trị ổn định. Vô kinh sau điều trị là $9,1 \%$. Các bất thường khác không ghi nhận như xơ phổi, ung thư hay tử vong.

\section{KẾT LUÂN}

Kết quả cho thấy sau điều trị bệnh nhân đã cải thiện rõ̃ rệt các triệu chứng lâm sàng, xét nghiệm, miễn dịch và chỉ số hoạt động SLEDAI. Trong đó thay đổi về chỉ số SLEDAI, DsDNA giảm rõ rệt có ý nghĩa thống kê. Protein niệu 24h giảm, mức lọc cầu thận tăng sau điều trị có ý nghĩa thống kế. Tỷ lệ đáp ứng thận đạt $60 \%$ (đáp ứng hoàn toàn $10,9 \%$, đáp ứng một phần $49,1 \%)$, không đáp ứng $40 \%$, tương tự với các nghiên cứu trên thế giới. Thuốc endoxan đường tĩnh mạch liều cao có ít tác dụng không mong muốn và dễ áp dụng cho $\mathrm{BN}$ trong điều kiện của nước ta.

\section{TÀI LIỆ THAM KHẢO}

1. Liệu, Đ.T., Nghiên cứu đối chiếu lâm sàng và mô bệnh hơc ở bệnh nhân viêm thận do bệnh lupus ban đỏ hệ thống. 2001, Học viện Quân Y: Hà Nôi.

2. chairat Shayakul, L.0.-a.-y., Phisit Chirawong, et all, Lupus nephritis in Thailan: Clinicopathologic Findings and Outcome in 569 patients. American Journal of Kidney Diseases, 1995. 26(2): p. 300-307.

3. Fanouriakis $A$, e.a., 2019 Update of the joint European League Aagainst Rheumatism and European Renal Association- European Dialysis and Tranplant Association (EULAR/ERA/EDTA) recommendations for the management of lupus nephritis. Ann Rheum Dis, 2020. 79: p. 713-723.

4. Pagnoux, C., Plasma exchange for lupus erythematosus. Transfus Apher Sci, 2007. 36: p. 187-193.

5. Zihong Liu, H.Z.e.a., Multitarget Therapy for Induction Treatment of Lupus Nephritis. A Randomized, Controlled Trial. Ann Intern Med. doi:10.7326/M14-1030, 2014.

6. Lewis EJ, H.L., Lan SP, Rohde RD, Lachin JM., A controlled trial of plasmapheresis therapy in severe lupus nephritis. The Lupus Nephritis Collaborative Study Group. N Engl J Med., 1992. 326: p. 1373-9.

7. Leyla Gadakchi, e.a., Efficacy and Safety of Mycophenolate Mofetil Versus Intravenous Pulse Cyclophosphamide as Induction Therapy in Proliferative Lupus Nephritis. Iranian Journal of Kidney Diseases, 2018. Volume 12(5): p. 288-92.

8. Ramaswamy Subramanian, H.P., Vinod Ravindra, Safey of Cyclophosphamide Therapy in Autoimmune Rheumatic Diseases.Indian Journal of Rheumatology, 2019. 14: p. 127-35. 